\title{
Manutenção dos recursos naturais na floresta nacional do bom futuro e seu entorno, Rondônia, Brasil
}

\author{
Juliene Moreira Novais' , Andreza Pereira Mendonça², Lorena Lorrayne Estevão Marinho³, \\ Adrielen Moraes Corti ${ }^{4}$, Raissa Fonseca Ferreira ${ }^{5}$ \\ 1, 2, 3, 4, 5 Fundação Universidade Federal de Rondônia, Porto Velho
}

\section{Resumo}

No Brasil são registradas 65 Florestas Nacionais, sendo 32 destas localizadas na Amazônia Legal, representando 3,13\% do total de unidades federais dessa região. Em Rondônia, foram criadas 3 FLONAS (Bom Futuro, Jamari e Jacundá), sendo que há pouca informação sobre o estado de conservação dessas unidades. Dessa forma, o objetivo geral do trabalho foi avaliar a manutenção dos recursos naturais na Flona do Bom Futuro e seu entorno, localizada na porção noroeste do estado de Rondônia, nos períodos de 1986 a 2011 por meio do geoprocessamento de imagens. O processamento digital de imagens, obtenção de métricas de paisagem e localização da área foram realizadas a partir da utilização dos softwares Sistema de Processamento de Informações Geográficas (Spring), versão 5.1.8 disponível gratuitamente pelo Instituto de Pesquisa Espacial - INPE do Brasil, sítio < http://www.dpi.inpe.br/spring/> e GVSIG, versão 1.9, obtendo-se o mapeamento dos dados em escala de 1:50000. Utilizou-se o Modelo da Terra South American Datum (SAD-69) e o Sistema de Projeção Universal Transversa de Mercator (UTM). Todo o procedimento para cálculo das áreas foi realizado com a zona de amortecimento de 10Km, sendo assim o plano de informação representou 606.000 ha para os três primeiros anos analisados (1986, 1996 e 2006) e de aproximadamente 389.576ha para o ano de 2011, devido a redução da Flona. O estudo demonstrou um crescente aumento da ocupação antrópica e queimadas, em decorrência a diminuição da vegetação. Evidenciou também, que a redução da Flona não contribuiu com a manutenção dos recursos naturais.

Palavras-chave:: unidade de conservação, análise multitemporal, geoprocessamento, ocupação antrópica.

\begin{abstract}
In Brazil are recorded 65 National Forests (Flonas), with 32 of these located in the Amazon, representing 3.13\% of total federal units that region. In Rondônia,3 Flonas were created (Bom Futuro, Jamari e Jacundá), and there is little information on the conservation status of these units. Thus, the overall objective was to avaliate the maintenance of natural resources in Flona Bom Futuro and its surroundings, located in the northwestern portion of the state of Rondônia, in the periods 1986-2011 through geoprocessing. The digital image processing, obtaining landscape metrics and location of the area were made using the software Processing Geographic Information Systems (Spring), version 5.1.8 that is available for free by the Institute for Space Research - INPE of Brazil website <http://www.dpi.inpe.br/spring/> and gvsig, version 1.9, obtaining data mapping on a scale of 1: 50000. It was used the model of the Earth South American Datum (SAD- 69) and the Universal Transverse Mercator Projection System (UTM). The entire procedure for calculation of areas was performed with the buffer zone of $10 \mathrm{~km}$, thus the information represented 606.000ha plan for the first three years analyzed (1986, 1996 and 2006) and approximately 389.576ha for the year 2011, due to reduction Flona. The study showed an increasing of anthropogenic fires and occupation, due to decreased vegetation. Also showed that the reduction of Flona not contributed to the maintenance of natural resources.
\end{abstract}

Keywords: conservation area, multitemporal analysis, geoprocessing, human occupation. 


\section{INTRODUÇÃO}

O processo de ocupação na Amazônia Legal tem sido marcado pelo desmatamento, pela degradação dos recursos naturais e por conflitos sociais. Em pouco mais de três décadas de ocupação, o desmatamento atingiu 18\% do seu território. Além disso, extensas áreas de florestas sofreram degradação pela atividade madeireira predatória e incêndios florestais (VERÍSSIMO et al., 2011).

O governo brasileiro vem tomando medidas para organizar e controlar a exploração desordenada dos recursos naturais a partir da criação e implementação de unidades de conservação (SCHNEIDER et al., 2000). O Sistema Nacional de Unidades de Conservação (SNUC) por meio da Lei $n^{\circ} 9.985$ de 18 de julho de 2000 prevê a implantação de unidades de conservação para garantir condições necessárias de proteção e conservação dos recursos naturais e das populações tradicionais.

As unidades de conservação são divididas em dois grupos, as de uso sustentável e as de proteção integral. As unidades de proteção integral e uso sustentável são divididas em cinco e sete categorias, respectivamente. Dentre as categorias de uso sustentável, encontra-se a Floresta Nacional (Flona).

A Flona é geralmente extensa e visa o uso múltiplo dos recursos florestais, com ênfase para exploração sustentável das florestas nativas, pesquisa científica e é permitida a permanência de populações tradicionais. A unidade quando criada pelo Estado ou Município, será denominada, respectivamente, Floresta Estadual e Floresta Municipal (BRASIL, 2000).

No Brasil, foram criadas 65 Florestas Nacionais, sendo 3 pertencentes ao estado de Rondônia (Jamari, Bom Futuro e Jacundá, criadas em 1984, 1988, e 2004, respectivamente) que ocupam uma área total de 540.716,35ha, (2,9\% do Estado), onde apenas a Flona do Bom Futuro não possui plano de manejo (GTA, 2008). Há pouca atenção a essa categoria quanto a gestão dos recursos naturais bem como medidas que monitorem o uso desses recursos. A Flona do Bom Futuro é um bom exemplo da necessidade de medidas que possibilitem a manutenção dos recursos naturais (BERNINI et al., 2009).

Dentre as medidas que ajudam a melhorar e dinamizar a gestão das unidades de conservação, o geoprocessamento é uma importante ferramenta para a obtenção de informações necessárias nas tomadas de decisão. O uso de geotecnologias possibilita o monitoramento da área e ações de prevenção e combate as invasões realizadas no interior das unidades e direciona os estudos ao conhecimento de possíveis áreas vegetadas com tendência ao desmatamento (BERNINI et al., 2009).

A Área de Proteção Ambiental do Capivari-Monos, em São Paulo, possui um banco de dados geográficos, possível de continua atualização que colabora no cotidiano da gestão da área e conscientização dos atores envolvidos com o processo (JACINTHO, 2003).

Dessa forma, o geoprocessamento é uma alternativa viável para monitorar as áreas protegidas de maneira eficaz, rápida e de baixo custo comparadas às metodologias tradicionais. O conhecimento temporal dos padrões de uso e cobertura da terra de unidades de conservação auxiliaria no planejamento e gestão de áreas públicas (TORRES, 2011).

Diante do exposto, o trabalho teve como objetivo avaliar a manutenção dos recursos naturais na Flona do Bom Futuro e seu entorno, localizada na porção noroeste do estado de Rondônia, nos períodos de 1986 a 2011 por meio de imagens de satélites.

\section{MATERIAIS E MÉTODOS}

A Flona do Bom Futuro foi criada por meio do Decreto ${ }^{\circ}$ 96.188, de 21 de junho de 1988, com área estimada em 280.000 ha, localizada na porção noroeste do Estado de Rondônia, nos municípios de Porto Velho e Buritis (FIGURA 1). O clima predominante nessa região é o tropical úmido e quente, com temperatura em torno de $25,9^{\circ} \mathrm{C}$ (SEDAM, 2010).

A unidade está inserida no bioma Amazônico e a vegetação é composta principalmente por floresta ombrófila, localizada na bacia do Rio Madeira. A unidade está situada no divisor de águas da microbacia do rio Candeias do Jamari e Rio Branco (MMA, 2013).

A manutenção dos recursos naturais da Flona foi avaliada por meio da análise resultante do processamento digital de imagens e por consulta dos documentos/legislações pertinentes a unidade.

Para o processamento digital de imagens, obtenção de métricas de paisagem e localização dos pontos, foram utilizados os softwares Sistema de Processamento de Informações Geográficas (Spring), versão 5.1.8 disponível gratuitamente pelo Instituto Nacional de Pesquisa Espacial (INPE) do Brasil, 


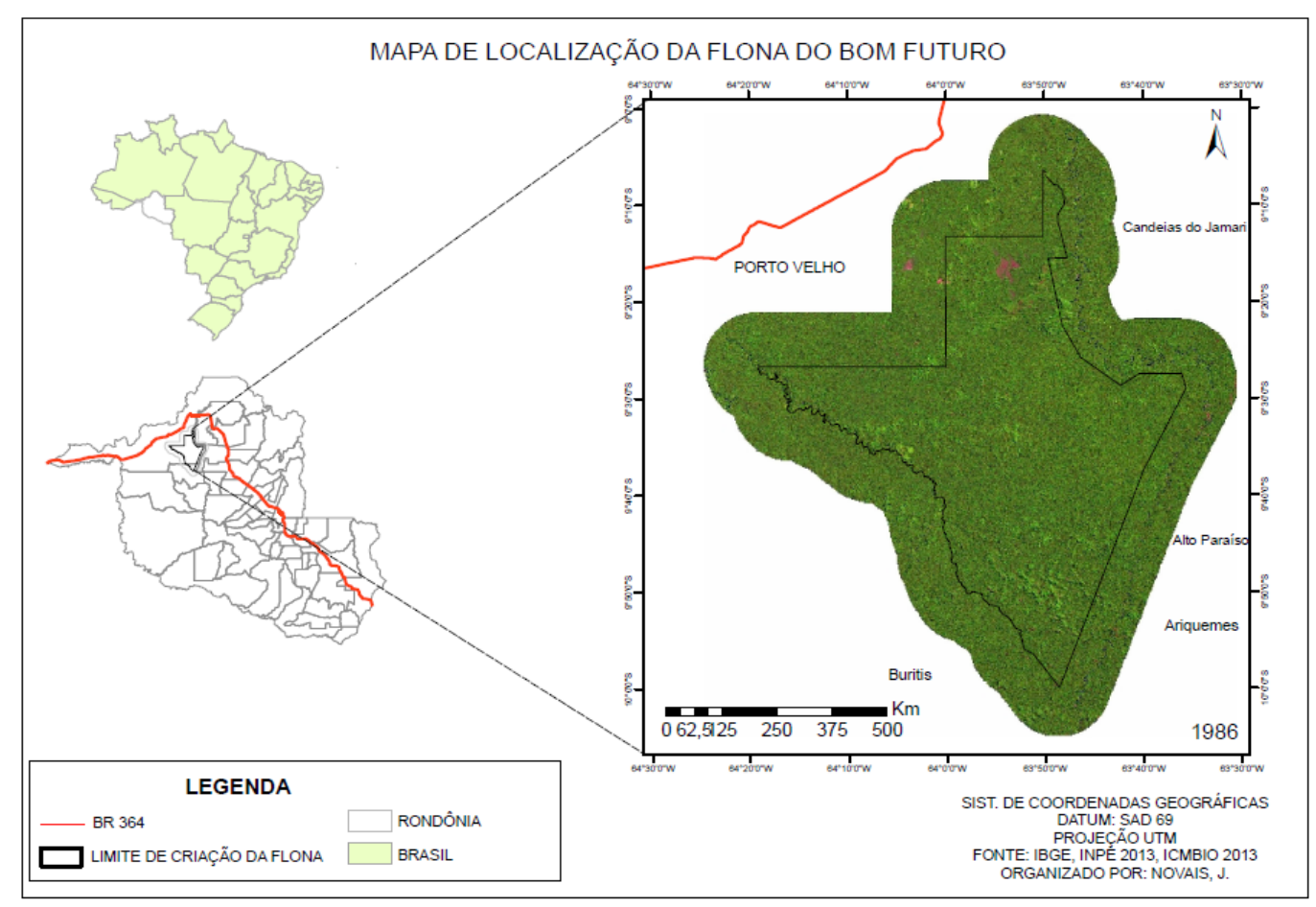

Figura 1 - Mapa de localização da Flona do Bom Futuro.

através do sítio <http://www.dpi.inpe.br/spring/> e GVSIG, versão 1.9, obtendo-se o mapeamento dos dados em escala de 1:50000. Utilizou-se o Modelo da Terra South American (Datum SAD 69) e o Sistema de Projeção Universal Transversa de Mercator (UTM).

Todo o procedimento para cálculo das áreas foi realizado com a zona de amortecimento de $10 \mathrm{Km}$, de acordo com a Lei $\mathrm{n}^{\circ} 9.985$ de julho de 2000, uma vez que o entorno influencia significativamente dentro da unidade. Dessa forma, o plano de informação representou 606.000ha para os anos de 1986, 1996 e 2006, e aproximadamente 389.576ha para 2011, devido a redução da Flona em 2010.

As etapas para o processamento digital das imagens foram, respectivamente, a obtenção das imagens e dos shapefiles (formato de arquivos), registro, mosaico, recorte, contraste, restauração, segmentação, classificação e mapeamento das classes.

As imagens utilizadas foram adquiridas do satélite Landsat série 5 (órbita/ponto 232-66 e 23267), sensor TM (Thematic Mapper), disponibilizado gratuitamente pelo INPE do Brasil, por meio do sítio <http://www.inpe.br//>. O período obtido das imagens foi entre os meses de junho e agosto dos anos de 1986, 1996, 2006 e 2011 com resolução espacial de 30 metros. Foram utilizadas imagens até o ano de 2011, pois não há disponibilidade de imagens mais recente. Para cada imagem, foram utilizadas as bandas espectrais B3 (vermelho), B4 (infravermelho próximo) e B5 (infravermelho médio). Os shapefiles da unidade de conservação foram adquiridos por meio do acervo do ICMBio, disponível no sítio < http://www.icmbio.gov.br/portal/> e os de hidrografia e malha viária adquiridos do Instituto Brasileiro de Geografia e Estatística (IBGE).

As imagens foram registradas por meio da definição de pontos de controle comuns na imagem, ressalvando-se que, de acordo com Meneses et al. (2012), a precisão deste método depende da precisão dos pontos de controle.

A partir do módulo Impima, as imagens foram transformadas para o formato (.spg) para serem trabalhadas no programa Spring 5.1.8.

Foram coletados 18 pontos amostrais de controle para a realização do registro, com uma distribuição uniforme por toda a imagem. Posteriormente, realizou-se o mosaico para seleção da área de estudo e o recorte.

O contraste linear aplicado posteriormente ao recorte da área de estudo, contribuiu para a melhor visualização e identificação dos alvos e a restauração das imagens para 15 metros reduzindo 
as distorções introduzidas nas imagens pelo desgaste natural dos sensores.

A segmentação foi pelo método de crescimento de regiões, onde foram feitas várias combinações com o limiar de similaridade para que os polígonos delimitassem de maneira mais adequada os diferentes tipos de classes, sendo o limiar escolhido de 10 metros e a área de pixel 15 metros, para que em seguida a imagem fosse classificada.

O método de classificação utilizado foi o supervisionado, baseado em crescimento de regiões, que utiliza os polígonos segmentados para selecionar as classes definidas pelos usuários. O classificador utilizado foi o Bhattacharya, selecionando 7 tipos de classes temáticas: afloramento rochoso, água, areia, floresta densa, floresta aberta, queimada e ocupação antrópica. Essas categorias foram definidas devido às características morfométricas e os pigmentos observados nas imagens.

O limiar de aceitação foi de $95 \%$. Após definido as classes, elaborou-se o mapeamento da área de estudo. O mapeamento foi elaborado transformando a imagem classificada em temática e o cálculo das áreas classificadas ocorreu por meio da ferramenta medida de classes do Spring 5.1.8.

\section{RESULTADOS E DISCUSSÃO}

Em 1986 na porção noroeste de Rondônia existia apenas como área protegida a Terra Indígena Karitiana, sendo criada em 1988 a Flona do Bom Futuro e, em 1996, a Resex Jaci-Paraná (FIGURA 2).

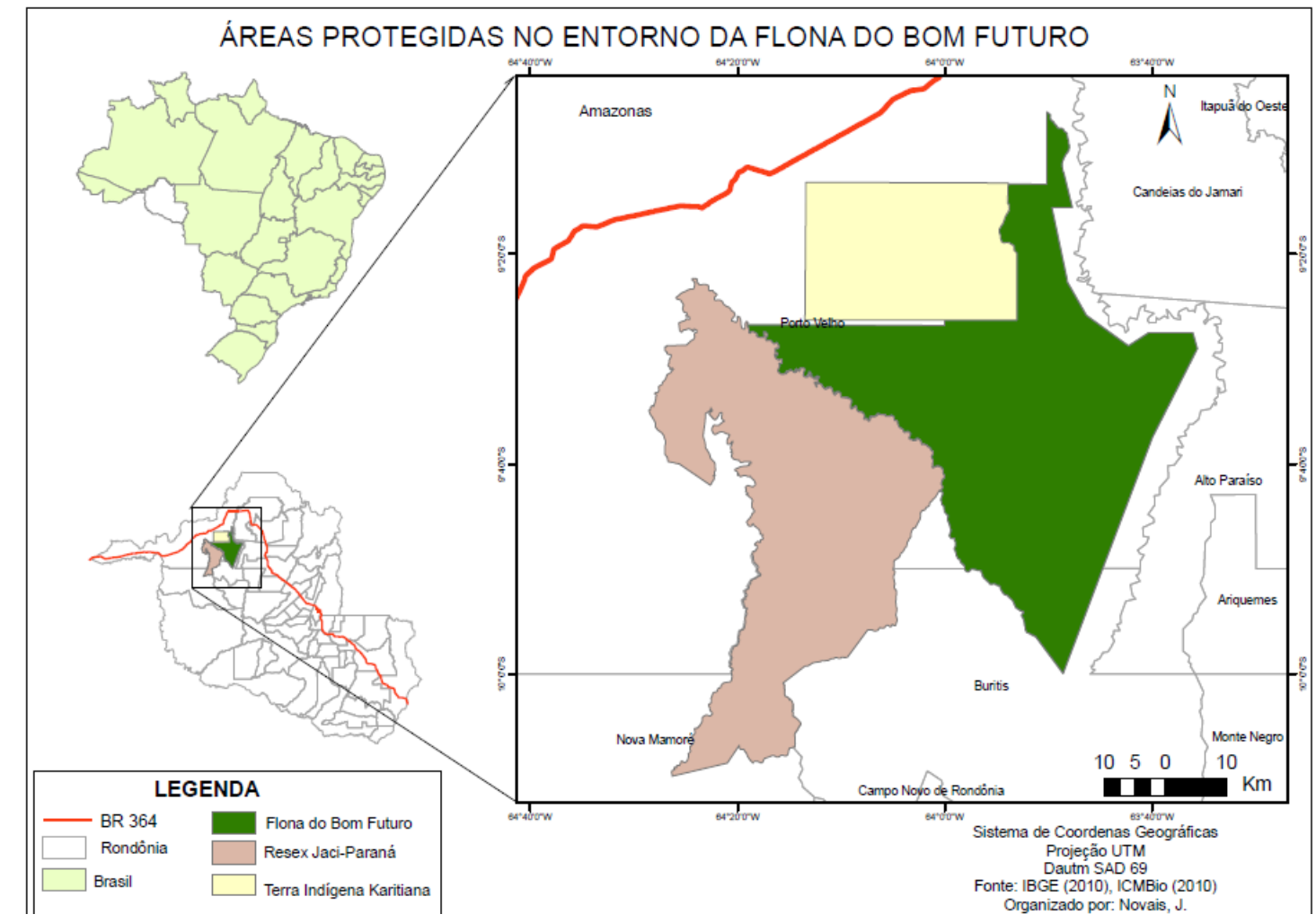

Figura 2 - Áreas protegidas que fazem divisa com a Flona do Bom Futuro.

No período de 1986 a 1996 observou-se na Flona seus recursos naturais conservados, não apresentando indícios de impacto ambiental antrópico, nem tão pouco demonstrou haver registro de populações tradicionais.

Após cinco anos da criação da unidade não houve a realização do plano de manejo, resultando em um processo de ocupação, a partir de 1996, por famílias que na maioria das vezes não sabiam que a área se tratava de uma unidade de conservação, pois não havia divulgação por parte dos órgãos ambientais responsáveis (FIGURA 3) (GOMES, 2013). 

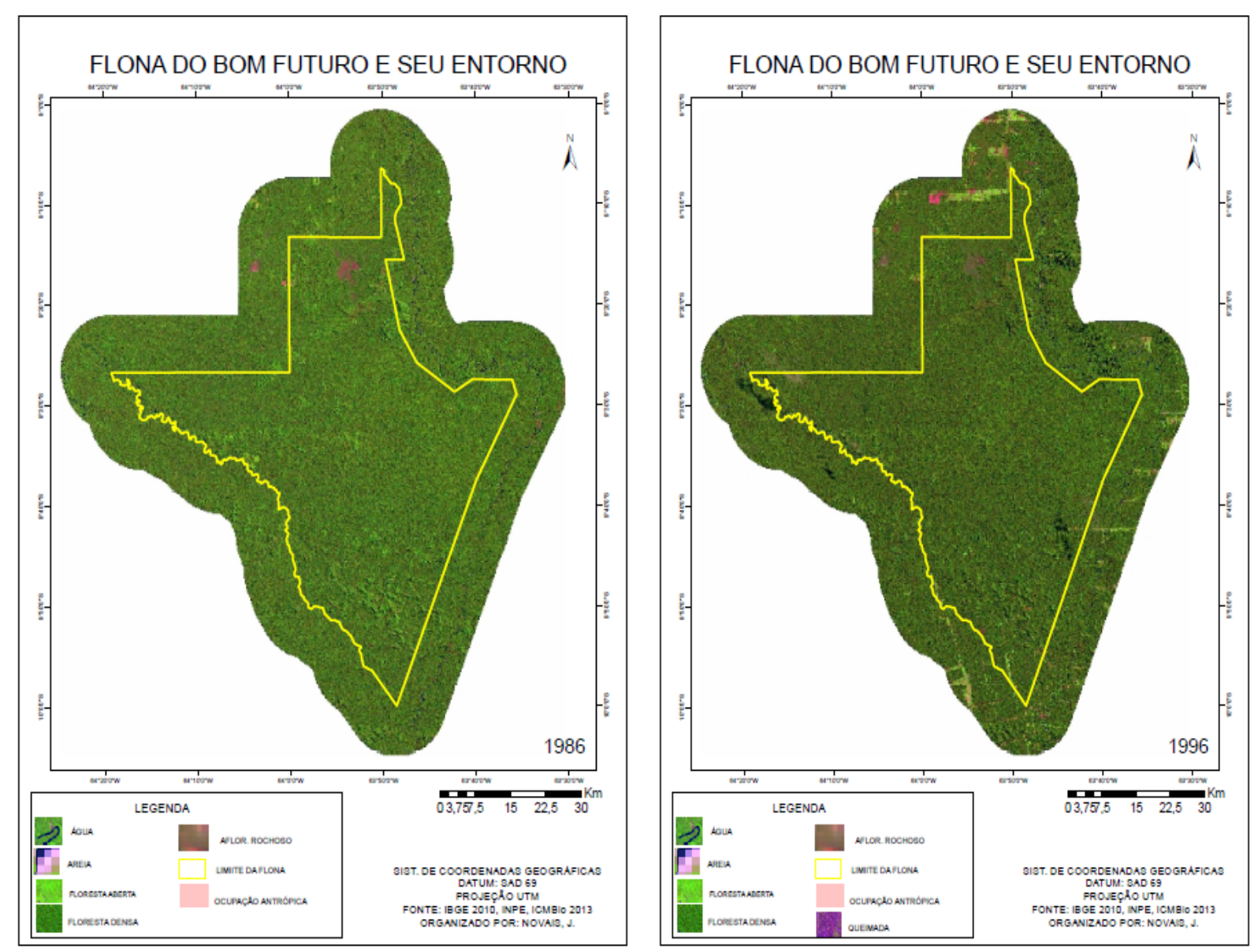

Figura 3 - Imagens da Flona do Bom Futuro e seu entorno nos anos de 1986 e 1996.

Apesar da lei nacional que obriga a implantação de planos de manejo em até cinco anos ter surgido somente no ano de 2000, as Flonas já eram regulamentadas pelo Decreto $\mathrm{n}^{\circ} 1.298$, de 27 de outubro de 1994. Esse Decreto estabelecia algumas diretrizes e metas, dentre elas, a implantação do plano de manejo em até cinco anos da criação da unidade, passíveis de revisão a cada dois anos, pelo IBAMA. É importante salientar que embora a legislação estabeleça um prazo de cinco anos para a realização do plano de manejo, não há indicação de qual será a consequência legal caso este prazo não seja cumprido.

No Brasil, o número de unidades de conservação federais que apresentam plano de manejo ainda é baixo, destacando as Flonas que das 65 criadas no país, apenas 16 possuem plano de manejo elaborados (ICMBio, 2013).

A ocupação na região da Flona Bom Futuro ocorreu ao longo da BR-364 e a medida que as terras foram ocupadas houve a interiorização nas proximidades da unidade. Isso pode ser explicado devido à proporção do desmatamento como função da distância das estradas na Amazônia Legal ter, normalmente, padrões exponenciais. Estudos demonstram que três quartos dos desmatamentos entre 1978 e 1994 ocorreram dentro de uma faixa de 100km de largura ao longo da rodovia BR-364 em Rondônia (FERREIRA, 2005; NEPSTAD et al., 2001).

Essa ocupação deu-se possivelmente devido a exploração de madeiras e minérios como a cassiterita e ainda, a formação de pastos, tornando sem efeito a legislação de proteção às unidades de conservação (NASCIMENTO, 2010). A Flona do Bom Futuro chegou a possuir mais de 6.000 famílias de agricultores distribuídas entre as três vilas constituídas: Marco Azul, Rio Pardo e Linha Saracura. A ocupação nessas vilas ficou evidente a partir do ano de 2006 (FIGURA 4), chegando a funcionar mais de dez serrarias na vila do Rio Pardo (GTA, 2008). Na área da Flona existiam 15 igrejas, 14 escolas 
rurais e mais de $300 \mathrm{~km}$ de estradas em ótimo estado de conservação e uma seção eleitoral situada na Vila do Rio Pardo (GOMES, 2013).

A intensa ação antrópica combinada à ocupação desordenada e as dificuldades de desocupação das famílias do interior da Flona, resultaram na expedição de uma liminar da justiça federal em 2009, paralisando todas as atividades no interior ou que fomentassem a invasão na Flona do Bom Futuro e demais unidades no seu entorno como a Resex Jaci-Paraná. A liminar não foi cumprida. $\mathrm{Na}$ ocasião, houve confronto armado entre os invasores e as equipes do IBAMA e de outros órgãos de fiscalização na via de acesso à Flona. A ação de grileiros que passaram a operar na Flona e no seu entorno, promoveram a implantação de loteamentos dentro da unidade (GTA, 2008).

O auge da ocupação ilegal da Flona deu-se no ano de 2010, resultando na redução dos limites por meio da Lei $\mathrm{n}^{\circ} 12.249$ de 11 de junho de 2010 , reduzindo os limites da unidade de 280.000 ha para 97.357ha (FIGURA 4).
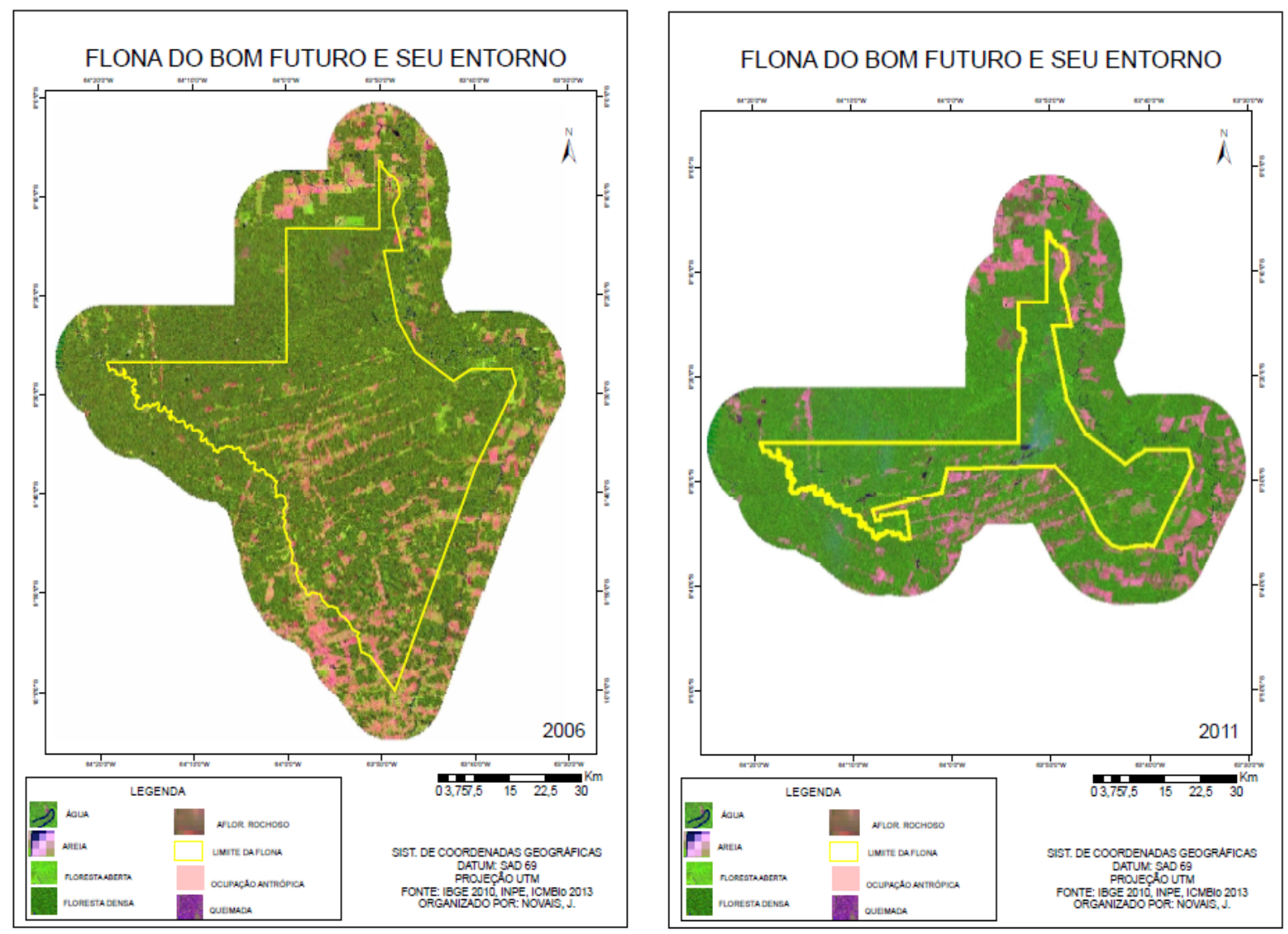

Figura 4 - Imagem da Flona do Bom Futuro e seu entorno nos anos de 2006 e 2011.

A ação antrópica ficou evidente à medida que foram realizadas as análises das classes temáticas. O aumento expressivo da ocupação antrópica foi visualizado no intervalo entre os anos de 1996 e 2006, atingindo $70.210,1$ ha (11,6\% da área) (FIGURA 5).

Na Flona e seu entorno, o afloramento rochoso representou, no ano de 1986, 2.664,6ha e 2.542,9ha no ano de 2011, pois a área atual da Flona possui a maior parte desse recurso (FIGURA 5). A diminuição dos valores de algumas classes no ano de 2011 foi resultado da redução da área da unidade em cerca de $65 \%$ da área inicial da Flona.

A classe areia aumentou de 21,7ha no ano de 1986 para 60,4ha no ano de 2011, evidenciando o assoreamento ao longo dos rios ocasionados pela retirada de cobertura vegetal. Consequentemente, houve a redução de cerca de 1000 ha do corpo hídrico entre os anos de 1986 e 2006 . No ano de 2011 a perda foi de 800 ha comparada ao ano de 2006, devido a redução dos limites da unidade (FIGURA 5).

A alteração de ambientes por mudanças de origens antrópicas podem contribuir para a deses- 
tabilização hídrica, uma vez que o desmatamento diminui a área de floresta, e por consequência a quantidade de água que retorna a atmosfera por meio da evapotranspiração, ocasionando a diminuição de chuvas (JOLY, 2007).

A floresta densa representava 98\% da área da Flona e entorno em 1986 e diminuiu para 84\% no ano de 2011. Observou-se a diminuição da classe floresta densa em decorrência ao aumento da classe floresta aberta (FIGURA 5).

Em 2011, o índice de ocupação antrópica na área de estudo atingiu a sua maior porcentagem 54.742 .1 ha (14\%). Houve o aumento no índice de queimadas com o passar dos anos, chegando a 1.301,5ha no ano de 2011 (FIGURA 5). O problema foi evidenciado com a retirada da floresta para formação de pastos.

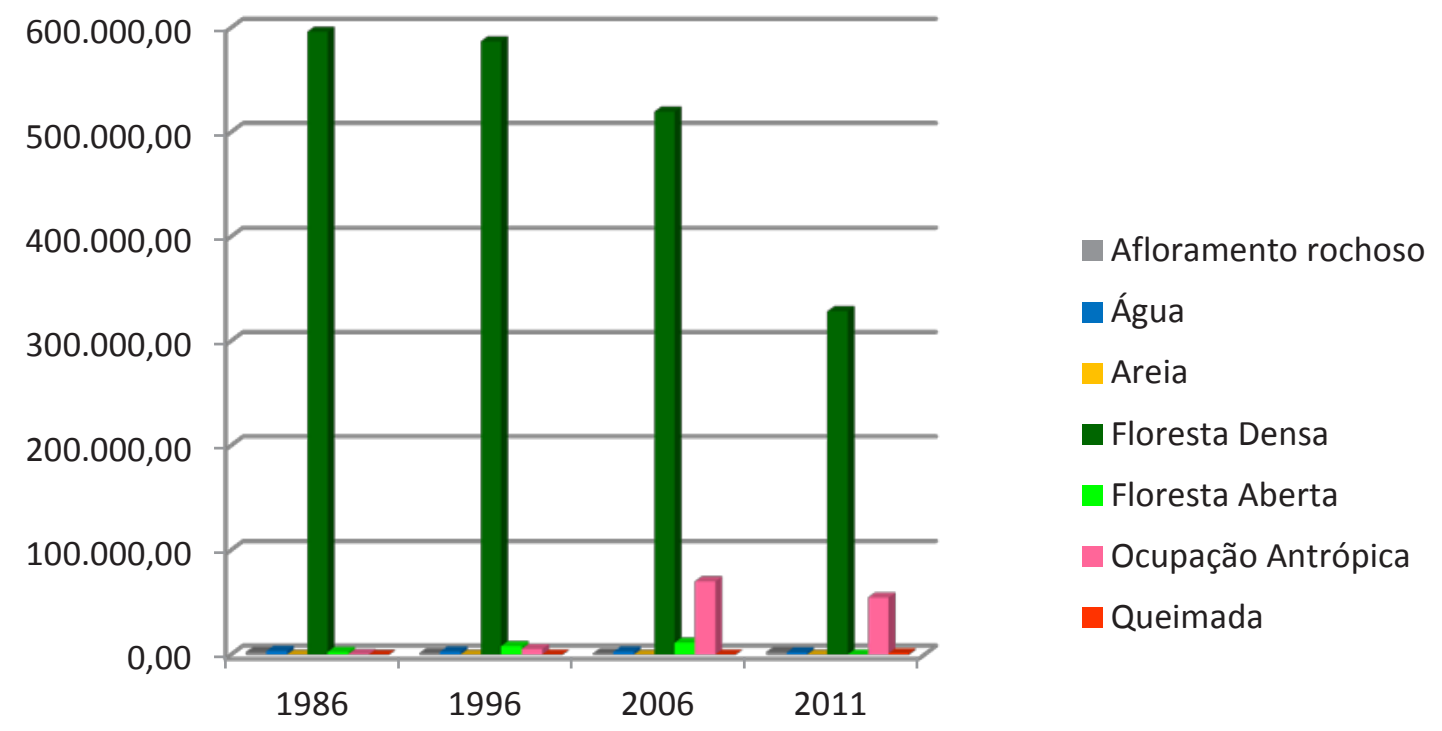

Figura 5 - Gráfico com os valores das classes analisadas no período de 1986 a 2011.

Na área reduzida da Flona foram criadas a APA (Área de Proteção Ambiental) do Rio Pardo e a FERS (Floresta Estadual de Rendimento Sustentável) do Rio Pardo por meio da Lei complementar $\mathrm{n}^{\circ} 581$ de 30 de junho de 2010, porém sem definição dos limites de cada unidade. Até o ano de 2010, parte da unidade $(28.831 \mathrm{ha}$ ) era sobreposta a Terra Indígena (TI) Karitiana, porém com a promulgação da Lei 12.249 de 2010 essa área foi suprimida e repassada para ampliação dos limites da TI Karitiana (GOMES, 2013)

A redução de unidades de conservação é uma prática comum realizada pelo governo de Rondônia a fim de resolver conflitos em áreas protegidas. Estudo realizado pelo IMAZON apontou que entre os anos de 2005 e 2010 foram alteradas 21 unidades de conservação, sendo 7 reduzidas e 14 extintas. As supressões foram realizadas para beneficiar projetos de infraestrutura e agropecuários (ARAÚJO e BARRETO, 2011).

Com a supressão da cobertura vegetal, perdeu-se o potencial madeireiro e o estado deixou de ganhar com a produção sustentável por meio das concessões florestais. Dentre as vantagens da concessão florestal para iniciativa privada, encontra-se a disponibilidade de terras fornecidas pelo governo para produção de madeira legalizada, bem como a garantia de estoques de matéria-prima no mercado (SIMONIAN, 2003).

O fogo também é usado como ferramenta de manejo agropecuário. Estudo realizado no Parque Nacional da Serra da Canastra apresenta um padrão com elevada frequência de incêndios ocasionados pelo manejo de pasto por meio do uso do fogo, atingindo grandes áreas, na estação seca (MEDEIROS e FIEDLER, 2011). As queimadas estão associadas também aos incêndios florestais. Das 308 unidades de conservação da Amazônia, em pelo menos 40 os satélites do INPE detectaram focos de incêndio no mês de agosto do ano de 2008 (THENÓRIO, 2008). Deve-se ressaltar ainda que faltam estruturas 
e mão de obra treinada para combater incêndios nas unidades de conservação no estado de Rondônia (VERÍSSIMO et al., 2011).

O governo mantêm os mesmos equívocos nas áreas protegidas, não há registro de campanhas de conscientização da população quanto a redução da Flona e a criação da FERS e APA, nem tão pouco há fortalecimento das unidades por meio dos conselhos gestores. O conselho consultivo interliga os setores sociais diretamente relacionados com as unidades de conservação, constituindo para isso um ambiente de debate sobre os problemas e demandas da área, procurando soluções por meio de negociações, de divisão de responsabilidades e estabelecimento de parcerias. Além disso, o conselho pode contribuir na elaboração de planos de manejo (DICK et al., 2012).

Salienta-se também a importância da realização de consulta pública e de audiência pública sobre a criação de unidades de conservação. A redução dos limites da Flona é um exemplo da ineficiência do governo em manter as áreas protegidas, visto que a supressão de área impede a formação de corredores ecológicos, impedem a formação de corredores ecológicos, que são de grande importância para manutenção da biodiversidade e preservação das espécies. Ė importante frisar que Rondônia embora tenha unidades próximas ou sobrepostas não consegue manter os recursos naturais, nem tão pouco salvaguardar os recursos por meio de corredores ecológicos.

No estado do Espírito Santo, por exemplo, existe o Projeto Corredores Ecológicos que visa a promoção de atividades sustentáveis, como a agricultura ecológica, os sistemas agroflorestais e o turismo sustentável em todo o estado, em especial nos dez corredores ecológicos e no entorno das UC's, mantendo as áreas protegidas. Além disso, estimulou a geração de renda para as comunidades locais a partir do comércio de produtos ambientalmente sustentáveis (MMA, 2007).

Estudo realizado por Brito (2008) no Amapá apontou que as unidades criadas sem a participação das populações envolvidas com a área eram palco de conflitos semelha aos identificados na Flona. Os principais conflitos nestas áreas são gerados pela utilização inadequadas dos recursos naturais como queimadas, desmatamentos, invasões, extrativismos ilegais (vegetal, animal e mineral), pecuária extensiva, agricultura predatória além de indefinição fundiária (DRUMMOND et al., 2010).

Um instrumento que pode auxiliar na gestão das unidades de conservação é a aplicação da ferramenta Cadastro Ambiental Rural (CAR). O CAR é um registro eletrônico de abrangência nacional junto ao órgão ambiental competente, no âmbito do Sistema Nacional de Informação sobre Meio Ambiente - SINIMA, obrigatório para todos os imóveis rurais, com a finalidade de integrar as informações ambientais das propriedades e posses rurais, compondo base de dados para controle, monitoramento, planejamento ambiental e econômico e combate ao desmatamento (Decreto $\mathrm{n}^{\circ} 7.830$, de 17 de outubro de 2012).

A implantação do CAR pode facilitar a identificação de áreas potencias para criação de Reserva Particular do Patrimônio Natural (RPPNs), por exemplo, diminuindo a fragmentação e colaborando com a formação de corredores ecológicos com as unidades já existentes. Desta forma, as informações referentes ao CAR podem ser utilizadas por órgãos como a SEDAM e ICMBio para gestão de unidades de conservação no estado.

No início de 2012, a SEDAM iniciou os trabalhos de CAR na Flona do Bom Futuro, identificando quais áreas já estavam ocupadas e quais áreas ainda possuíam remanescente de floresta nativa. Em setembro, iniciou a desocupação das famílias no interior da unidade, sendo algumas realocadas.

Também, com a utilização do CAR podem ser identificadas as reservas legais existentes e elaborar a recuperação de matas ciliares para que sejam utilizadas para interligar com as unidades de conservação, em especial a Flona do Bom Futuro que necessita de áreas verdes no seu entorno.

\section{CONSIDERAÇÕES FINAIS}

As Florestas Nacionais ainda representam importante fonte de manutenção dos recursos naturais no estado de Rondônia. Porém, são alvos frequentes de exploração ilegal, sendo assim, fazem-se necessárias medidas que assegurem a manutenção dos recursos naturais.

A gestão compartilhada deve ser estimulada pelos órgãos gestores das unidades em Rondônia, a fim de tornar efetiva a manutenção das áreas protegidas bem como estabelecer uma relação de con- 
fiança entre a população e o governo.

$\mathrm{O}$ uso de ferramentas geotecnológicas, em especial o CAR, pode ser eficaz para identificar as áreas que precisam ser recuperadas, as áreas que devem dar continuidade as unidades existentes e identificar áreas potencias para criação de novas áreas protegidas.

\section{SUGESTÕES}

Realização de campanhas de conscientização ambiental ("momento verde") como políticas públicas, destacando a importância da manutenção das áreas protegidas por meio da utilização de veículos de comunicação que alcance a população rondoniense. As campanhas complementariam as audiências públicas informando a população sobre as unidades de conservação, bem como evidenciaria as atividades desenvolvidas pelo governo em relação às áreas protegidas.

A criação de um balcão de negócios de produtos e serviços oriundos de áreas manejadas estimularia o desenvolvimento de atividades legalizadas no estado, consequentemente, fortaleceria a manutenção das áreas protegidas.

\section{AGRADECIMENTO}

Agradecemos ao Núcleo de Estudos em Agroecologia do Instituto Federal de Rondônia, Câmpus Ji-Paraná.

\section{REFERÊNCIAS}

ARAÚJO, E. \& Barreto, P. 2011. Ameaças formais contra as Áreas Protegidas na Amazônia. Estado da Amazônia n.16. Belém: Imazon, 6p. Disponível em: http://bit.ly/cQvLma

BERNINI, H., MARININI, G.B.S., FILHO, E.P.S., 2009. Monitoramento do Desmatamento no período de 2000 a 2007 na Floresta nacional do Bom Futuro: estudo de caso Linha 2 da Zona Vila do Rio Pardo. Universidade Federal de Rondônia - UNIR.

BRASIL. Lei no 9.985 , de 18 de julho de 2000. Lei do Sistema Nacional de Unidades de Conservação da Natureza. Disponível em: <http://www.planalto.gov.br/ccivil/leis/L9985.htm>. Acesso em 04 de maio de 2013.

BRASIL. Lei nº 12.249, de 11 de junho de 2010. Lei que altera os limites da Flona do Bom Futuro.

Decreto $n^{\circ}$ 96.188, de 21 de junho de 1988. Cria no Estado de Rondônia a Floresta Nacional do Bom Futuro com limites que especifica e dá outras providências.

DICK, E.; DANIELI, M. A.; ZANINI, A. M. Gestão participativa em Unidades de Conservação: uma experiência na Mata Atlântica. Rio do Sul, SC : APREMAVI, 2012.

DRUMMOND, J. A.; FRANCO, J. L. DE A.; OLIVEIRA, D. DE. Uma análise sobre a história e a situação das unidades de conservação no Brasil. , p. 341-385, 2010.

FERREIRA et al. O desmatamento na Amazônia e a importância das áreas protegidas, 2005.

GTA. O Fim da Floresta? A Devastação das Unidades de Conservação e Terras Indígenas no estado de Rondônia. Grupo de Trabalho amazônico, 2008.

GOMES, J. C. Relatório das ações para a efetividade de gestão das unidades de conservação denominadas 
Área de Proteção Ambiental e Floresta Estadual - APA/FES do Rio Pardo. Governo do estado de Rondônia. Secretaria do estado de desenvolvimento ambiental. Coordenadoria de unidades de conservação - CUC's. Porto Velho, 2013.

ICMBio, 2013. Unidades de Conservação Federais no Brasil. Disponível em: <http://www.icmbio.gov.br/ portal/biodiversidade/unidades-de-conservacao/biomas-brasileiros.html>. Acesso em agosto de 2013.

JACINTHO, L. R. DE C. Geoprocessamento e sensoriamento remoto como ferramentas na gestão ambiental de unidades de conservação: o caso da área de proteção ambiental (APA) do Capivari-Monos, São Paulo-SP. Dissertação de mestrado. Universidade de São Paulo, 2003.

JOLY, C. A. Biodiversidade e mudanças climáticas: contexto evolutivo, hitórico e político. Ambiente \& Sociedade. v. 10, n.1, Campinas, 2007.

MEDEIROS, BRILHANTE DE, MARCELO; FIEDLER, NILTON CEZAR. Incêndios florestais no Parque Nacional da Serra da Canastra: desafios para a conservação da biodiversidade. Acesso em: 17 de julho de 2013. Disponível em:<http://redalyc.org/articulo.oa?id=53414215> ISSN 0103-9954, 2011.

MENESES, P.; ROBERTO; ALMEIDA, T. Introdução ao Processamento de imagens de sensoriamento remoto. UNB, Brasília, 2012.

MMA, 2007. Corredores Ecológicos - experiências em planejamento e implementação/ Instituto do Meio Ambiente e dos Recursos Naturais Renováveis, Ministério do Meio Ambiente, Secretaria de Biodiversidade e Florestas. Brasília: MMA, 2007.

MMA, 2013. Ministério do meio ambiente. Disponível em: <http://www.mma.gov.br/areas-protegidas/ acoes-e-iniciativas/item/52>. Acesso em 26 de julho de 2013

NASCIMENTO, C. P. O Processo de Ocupação e Urbanização de Rondônia: Uma Análise das transformações sociais e espaciais. Revista de Geografia, p. 53-69, 2010.

NEPSTAD, D.; CARVALHO, G.; BARROS, A. C.; ALENCAR, A; CAPOBIANCO, J. B.; BISHOP, J; MOUTINHO, P.; LEFEBVRE, P. e SILVA, U. L. Road Paving, Fire Regime Feedbacks, and the Future of Amazon Forests. Forest Ecology and Management 5524, 2001, pp. 1-13.

SCHNEIDER, R.R.; ARIMA, E.; VERÍSSIMO, A. et al. Amazônia sustentável: limitantes e oportunidades para o desenvolvimento rural. 58p. Brasília: Banco Mundial; Belém: IMAZON, 2000.

SEDAM, 2010. Boletim Climatológico de Rondônia. Disponível em: <http://www.sedam.ro.gov.br/index. $\mathrm{php} /$ component/content/article/107-meteorologia/146-boletim-anual>. Acesso em 2 de agosto de 2013.

SIMONIAN, L. T. L., et al. FLORESTA NACIONAL DO AMAPÁ: breve histórico, políticas públicas e (in) sustentabilidade. Paper do NAEA, julho de 2003.

THENÓRIO, 2008. Globo Amazônia, São Paulo. Disponível em <http://www.globoamazonia.com/ Amazonia/0,,MUL844503-16052,00-fLORESTA+EM+RONDONIA+E+DEVASTADA+POR+INVASOES +E+DESMATAMENTO+ILEGAL.html>. Acesso em 20 de junho de 2013.

TORRES, D. R. Análise multitemporal do uso da terra e cobertura florestal com dados dos satélites Landsat e Alos. Dissertação de mestrado. Universidade Federal de Santa Maria, 2011

VERÍSSIMO, A. et al. Áreas Protegidas na Amazônia brasileira : avanços e desafios. Belém: Imazon; São Paulo : Instituto Socioambiental, 2011. 